\title{
Correction to: Distance measurements and origin levels of the coeliac trunk, superior mesenteric artery, and inferior mesenteric artery by multiple-detector computed tomography angiography
}

\author{
Arzu Ekingen ${ }^{1}\left[\right.$ - Eyüp Savaş Hatipoğlu ${ }^{2} \cdot$ Cihad Hamidi $^{3}$
}

Published online: 20 October 2020

(C) Japanese Association of Anatomists 2020

\section{Correction to: Anatomical Science International https://doi.org/10.1007/s12565-020-00571-x}

In the original publication of the article, the "Keywords" and Fig. 7 were published incorrectly. The correct "Keywords" and Fig. 7 are given in this correction.

Keywords Abdominal aorta $\cdot$ Anatomic variation $\cdot$ Coeliac trunk - Mesenteric arteries - Mesenteric artery, Inferior . Mesenteric artery, Superior - Multidetector computed tomography

The original article can be found online at https://doi.org/10.1007/ s12565-020-00571-x.

Arzu Ekingen

arzumumcu55@gmail.com

1 Vocational High School of Health Services, Batman University, Batman, Turkey

2 Department of Anatomy, Faculty of Medicine, University of Dicle, Diyarbakır, Turkey

3 Department of Radiology, Private Bağlar Hospital, Diyarbakır, Turkey

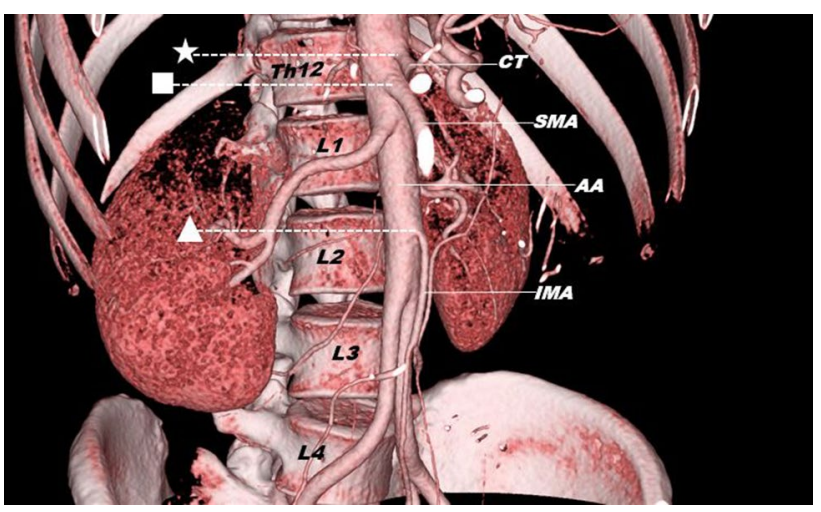

Fig. 7 Coeliac trunk originating from the abdominal aorta at middle level of the Th12 (star), the superior mesenteric artery originating from the abdominal aorta at lower level of the Th12 (square), the inferior mesenteric artery originating from the abdominal aorta at upper-level of the L2 (triangle) (35 age, male); $A A$ abdominal aorta, $C T$ coeliac trunk, SMA superior mesenteric artery, IMA inferior mesenteric artery

Publisher's Note Springer Nature remains neutral with regard to jurisdictional claims in published maps and institutional affiliations. 